\title{
The capacity-building and science-enabling activities of the IUGONET for the solar-terrestrial research community
}

\author{
Akiyo Yatagai ${ }^{1 *}$, Yuka Sato ${ }^{2}$, Atsuki Shinbori ${ }^{3}$, Shuji Abe ${ }^{4}$, Satoru UeNo ${ }^{5}$ and IUGONET project team
}

\begin{abstract}
Background: This paper presents an overview of the capacity-building activities and science-enabling services of the Inter-university Upper atmosphere Global Observation NETwork (IUGONET) project. This Japanese program, which started in 2009, is building a metadata database (MDDB) of ground-based observations and is developing an analysis software to handle the data linked to the MDDB system for use by the solar-terrestrial physics community. Because the institutional members of the IUGONET are mainly universities in Japan, we explore tools that can contribute to advanced education as well as promote research activities.
\end{abstract}

Findings: In this paper, we describe the utilities of the IUGONET for education, including our capacity-building activities in developing countries. We have regularly facilitated training seminars for Japanese students on the use of our tools (IUGONET MDDB and the software), and we have held capacity-building seminars for young scientists in developing countries. In addition to the MDDB, we have prepared various 'gateway' tools for users who are unfamiliar with 'keywords' to search for data. One of these is a geographical display tool that uses Google Earth (KML file), which is included as supplemental material to this paper. The usefulness of the IUGONET has been proven over its first 5 years of operation by the increasing number of its users, which has led to the production of approximately 500 scientific papers, including 42 thesis papers.

Conclusions: The IUGONET community collaborates with the Scientific Committee on Solar-Terrestrial Physics program, not only in its scientific activities, but also in the establishment of E-infrastructure and capacity building.

Keywords: Ground-based observation; Solar-terrestrial physics (STP); Database; Metadata; Interdisciplinary studies; Capacity building; E-infrastructure

\section{Findings}

Background of data activities of the STP community

The series of the Climate And Weather of the Sun-Earth System (CAWSES) projects of the Scientific Community on Solar-Terrestrial Physics (SCOSTEP) required considerable standardization efforts to unify the variety of ground-based and satellite-derived observational data obtained across disciplines and countries (CAWSES Office 2014; Davila and Tsuda 2014). The solar-terrestrial physics (STP) research community handles diverse data resources that span the globe, reach altitudes over $100 \mathrm{~km}$ into the heliosphere, and extend over many decades in

\footnotetext{
*Correspondence: akiyoyatagai@stelab.nagoya-u.ac.jp

'Solar-Terrestrial Environment Laboratory, Nagoya University, Furo-cho,

Chikusa-ku, Nagoya 464-8601, Japan

Full list of author information is available at the end of the article
}

duration. To complicate matters further, the sophistication of ground-based and spaceborne observatories for remote and in situ sensing of the STP domain results in the archives of these data resources being distributed among various organizations throughout the world. This has culminated in the long-standing challenges associated with centralized STP data exchange and distribution. It is the responsibility of the CAWSES program to preserve observational data that are spread across individual institutions and to help students and early career scientists from different backgrounds to obtain data relevant to their research.

The International Council of Scientific Unions (ICSU)/ World Data Center (WDC) for STP was established in 1957 to manage data collected during the International 
Geophysical Year (IGY, 1957 to 1958) to avoid catastrophic damage to all the observed geophysical data. This system has evolved over the approximately 60 years of its operation for the STP community, especially in Japan. The Space Physics Interactive Data Resource (NOAA National Geophysical Data Center 2014) of the former WDC for Solar-Terrestrial Physics, Boulder, in the National Geophysical Data Center (NGDC)/National Ocean and Atmosphere Administration (NOAA), is the pioneer database for archiving STP observational data. Satellite mission data from the upper atmosphere and heliosphere have been archived at the National Space Science Data Center (NSSDC) of the National Aeronautics and Space Administration (NASA) (Grayzeck 2014) since 1966. These include the Virtual Magnetospheric Observatory (VMO), Virtual Heliospheric Observatory (VHO), and Virtual Solar Observatory (VSO), which constitute satellite data archives for each field and are NASA projects that are grouped under the abbreviated name 'VxO.'

Solar data have been archived mainly at the VSO (Gurman 2014), and this system, which includes a data exchange function, has become a community tool for solar scientists.

In terms of the analysis system, the Coordinated Data Analysis (Workshop) Web system of NASA (McGuire 2014) enables researchers to handle key parameters and statistics of STP as well as observed data prepared by the $\mathrm{VxO}$. In the United States, for ground-based observations, the incoherent scatter radar community has started the Coupling, Energetics, and Dynamics of Atmospheric Regions (CEDAR) program database, and the CEDAR Madrigal database (Rideout 2014) is currently collecting international upper atmospheric observational data and/or metadata obtained in South America, Europe, China, and the United States, in addition to providing analysis software.

\section{Necessity for the IUGONET metadata system}

Long-term ground-based, i.e., stable, observational data are of considerable importance because the upper atmosphere is strongly affected by solar activity. The STP research community of Japan does not have any central institutions for data exchange and distribution, as mentioned above. Thus, the observational data from solar telescopes, various radars, optical instruments, and magnetometers are held mainly by the relevant institutions. This means that it is difficult for early career scientists from different backgrounds to obtain data for their research work. Hence, in 2009, the leading institutions of the National Institute of Polar Research, Tohoku University, Nagoya University, Kyoto University, and Kyushu University started the Inter-university Upper atmosphere Global Observation NETwork (IUGONET) project for managing ground-based observations of the upper atmosphere and the Sun.

The primary objective of the IUGONET project was to build a metadata database (MDDB) for ground-based observations of the upper atmosphere, which could be searched by a dedicated analysis software for relevant observed data (Hayashi et al. 2013). However, we deal with data pertaining to both the Sun as well as the upper atmosphere.

The IUGONET was quickly able to fulfill its original purpose of developing an MDDB and analysis software (Yatagai et al. 2014). Currently, the IUGONET is expanding to provide additional tools for related geoscience fields and the international CAWSES society, including developing countries, not just the member institutions and domestic Japanese STP community. The general activities of the IUGONET and developed products have been described elsewhere (Tanaka et al. 2013; Yatagai et al. 2014), including this volume (Abe et al. 2014).

The IUGONET project team has provided exhibitions at various meetings and committed considerable investments of time, manpower, and funds to enhance the capacity-building aspects of the data service for students of all levels, as well as established scientists unfamiliar with the IUGONET. Figure 1 shows the activities and general flow of the data in the IUGONET.

This paper will discuss the capacity-building and scienceenabling activities of the IUGONET because these have been important topics for the CAWSES-II program. We will first briefly describe the data resources and then outline our educational and capacity-building activities for developing countries. This will be followed by a statistical analysis of the science-enabling capability of the IUGONET, together with a discussion of the overarching objectives for future developments.

\section{Diversity of the IUGONET data resources}

The IUGONET MDDB is built as a metadata repository based on the Space Physical Archive Search and Extract (SPASE, King et al. 2010) model, which is widely used in the international STP community, such as NASA's VxOs. While the primary focus of the $\mathrm{VxO}$ projects is on satellite data, the IUGONET has made a systematic effort to acquire data resources from assorted groundbased instrumentation, including the digitization of analog data stored on paper and magnetic tapes. Thus, the IUGONET has become a unique repository of ground-based STP data at more than 860 observatories worldwide (Figure 2).

\section{IUGONET data search and various gateways}

The IUGONET metadata (MD) are written in XML format, and the style (or format) is defined for individual keywords (Observatory, Instrument, Person, Dataset, 


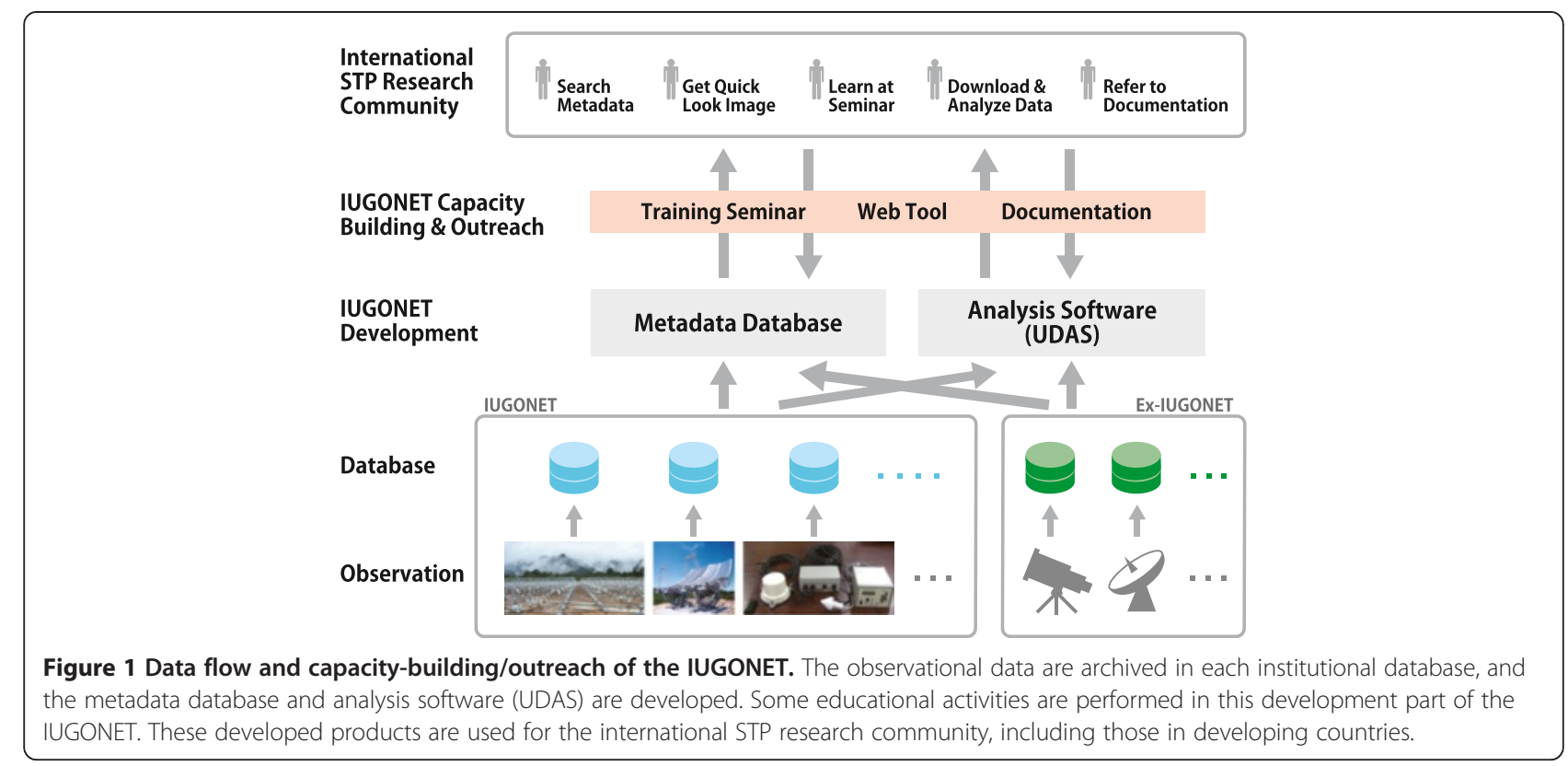

and Granule to reach each specific data file), in accordance with the SPASE ontology. Because these MD are formatted uniformly, conversion to another format (including KML) is relatively simple.

Figure 3 shows an example of how the Observatory MD function with Google Earth to display the information on the observation, for example, in the region including Kyoto and Nagoya, Japan. Many instruments at Shigaraki Observatory are displayed by browsing (not shown). For instance, if the Optical Mesosphere Thermosphere Imager (OMTI; an all-sky imager at Shigaraki) is chosen, the MD of the instrument appear on screen (Figure 3b). By

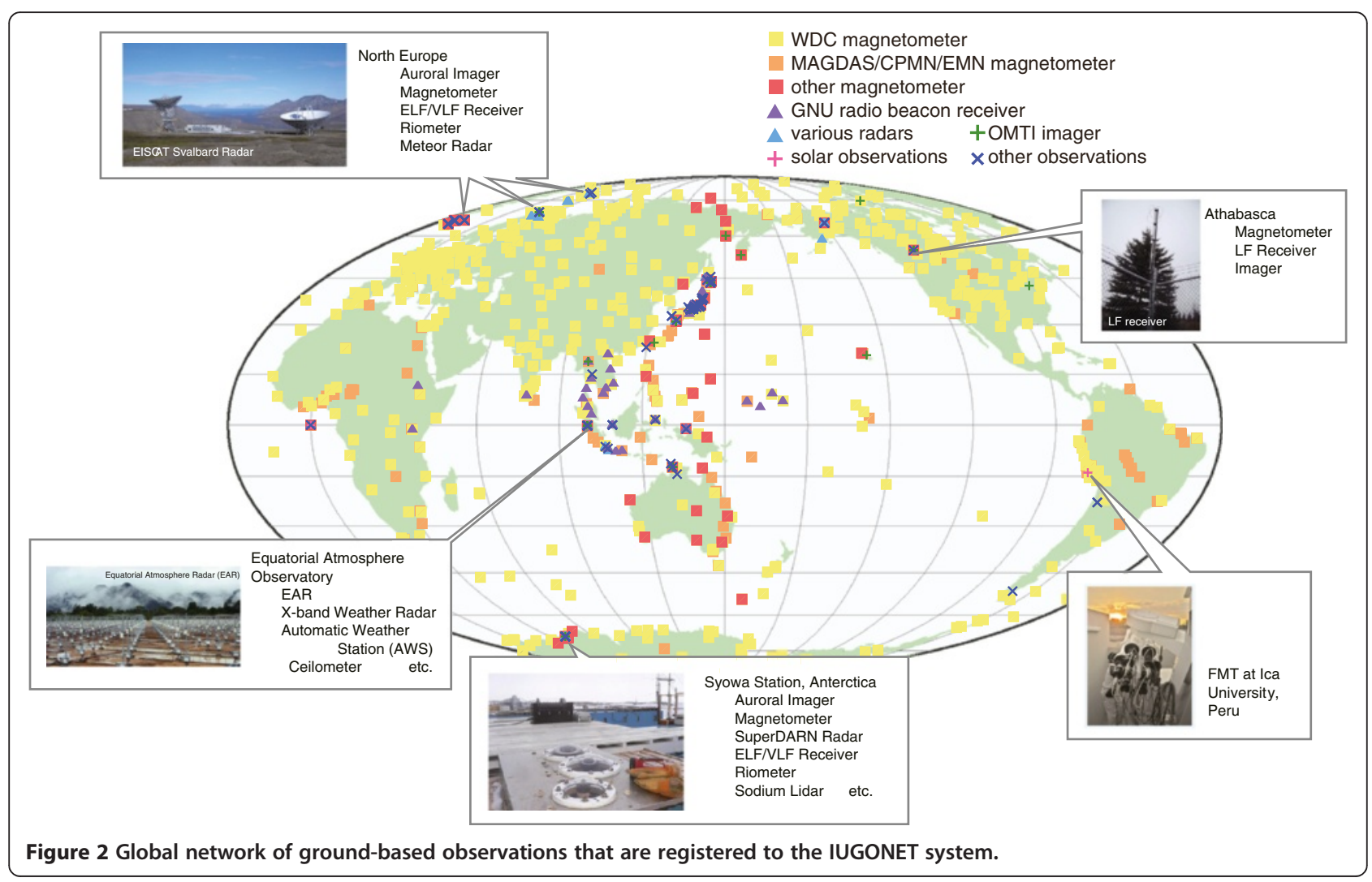


a)

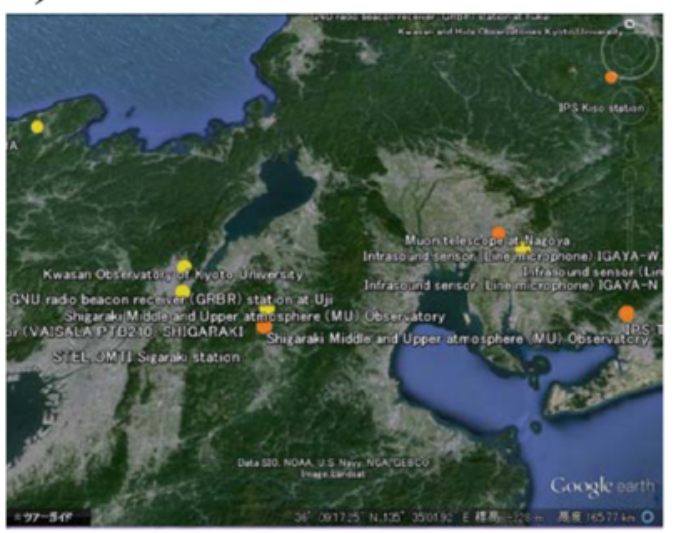

b)

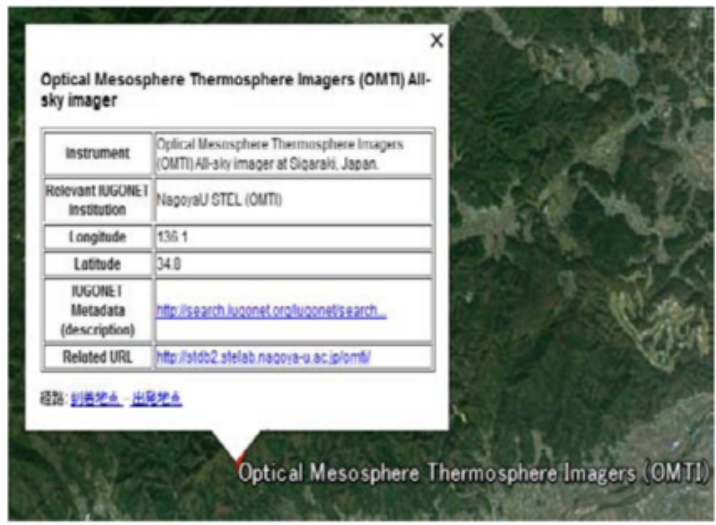

c)

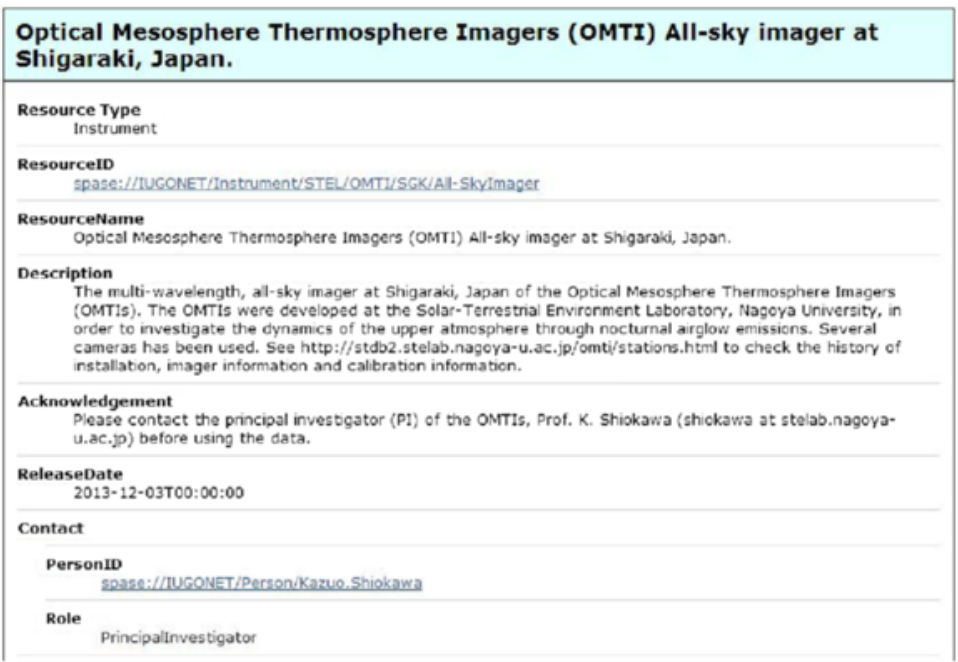

d)

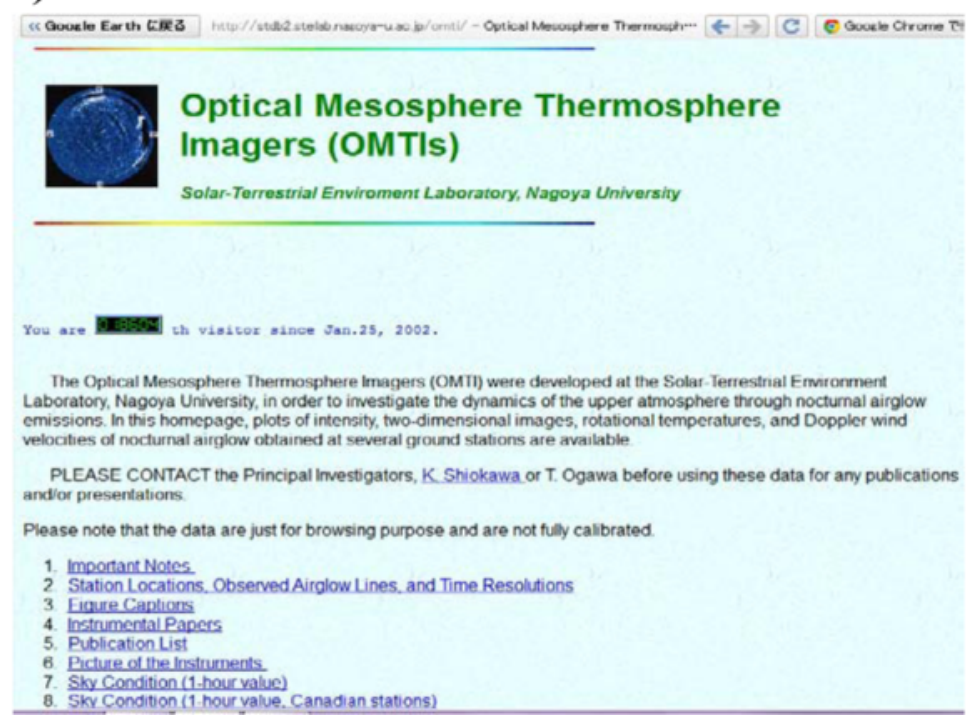

Figure 3 (See legend on next page.) 
(See figure on previous page.)

Figure 3 Observatories and instruments registered in IUGONET MDDB as viewed through Google Earth around Kyoto and Nagoya, Japan. (a) Observatories. Yellow indicates observatories operated by Kyoto University, and orange indicates those operated by Nagoya University. (b) Display of the metadata of the all-sky camera of OMTI at Shigaraki, offered by clicking 'Instrument' metadata viewed through Google Earth. (c) Result of search MDDB followed by clicking IUGONET Metadata (description) in (b). (d) Result of clicking 'Related URL' shown in (b).

clicking the associated web address, the user can obtain descriptions of the MD (Figure 3c) and related URLs, e.g., OMTI's webpage (Figure 3d).

From these tables and the KML file, users can easily recognize the types of data installed in the IUGONET MDDB and find appropriate keywords, for example, 'SuperDARN', 'OMTI', and 'all-sky camera'. The geographical tool mentioned above received much attention from scientists attending inter-disciplinary meetings and workshops (described later). We include this KML file, used for displaying the observatory and instrument MD, as supplementary material for this paper (see Additional files 1 and 2).

A team comprising ten $\mathrm{PhD}$-level researchers is affiliated with the IUGONET development team. They work to create the MD by extracting relevant information from scientific papers and technical documents and by interviewing the relevant data holders. Thus, all the IUGONET resources are linked to meta-information such as 'Description' and 'Keyword' text files, and new users can be navigated quickly to the wealth of data resources using the IUGONET tools. As illustrated earlier (Figure 3), the MD are valuable for explaining the data to newcomers and for various outreach/capacity-building activities.

We prepared a list of the registered MD (IUGONET 2014a) using a function of Google Spreadsheet, as shown in Figure 4. This provides users with knowledge of both types of data: those registered already in the MDDB and those in preparation for release. In addition, it is useful for newcomers as it offers them a selection of suggested keywords to be entered. This is because some keywords are linked to the search results of each deterministic portion of meta-information; therefore, this sheet is instructive in explaining our MDDB.

As shown in Figure 4, if an all-sky monochromatic image dataset is chosen (Figure 4a, red square), the MD of that dataset appear on the screen (Figure 4b), which provides users with a description of the data. If granule MD is registered (e.g., SuperDARN, Figure 4c), one can reach the original data without restriction. If the datahandling software, iUgonet Data Analysis Software (UDAS, described in the following) is available, this is written as 'Load routine for UDAS is available' in the column. By clicking the 'Note' shown on the screen (Load routine for UDAS is available), the user can go to the list of the 'load procedure' of UDAS (Figure 4d).

\section{Development and use of the UDAS software}

A suite of custom software was developed to support downloading, plotting, and analysis of data registered in the IUGONET database (IUGONET 2014b). The IUGONET does not regulate individual data formats employed by its member institutes. Instead, in collaboration with the Exploration of Energization and Radiation in Geospace Science Center (Miyoshi et al. 2012), we have developed the UDAS software to handle various types of formatted data using the same platform (Tanaka et al. 2013).

As a part of the IUGONET activities, an institutional educational program (Bachelor and Master's course level) participates in the development of an analysis package in the UDAS. For example, various types of statistical tests of significance have been incorporated into the UDAS (Hamaguchi 2013). The UDAS is useful not only for researchers in terms of handling data (downloading, producing graphs, analyzing), but also for participating in its development of the IUGONET system.

\section{Domestic training seminars and overseas capacity building}

The IUGONET has facilitated a series of domestic training seminars for the STP community's early career scientists, as well as more experienced researchers who want to handle data by means of a graphical user interface, on how best to use the UDAS (and MDDB). In addition to regular annual or biannual training seminars, IUGONET developers are conducting small training seminars at several universities.

As shown in Figure 2, IUGONET institutions have been performing ground-based observations for a long time and they have established many observatories throughout the world. To promote the use of our MDDB and the UDAS, we conducted training seminars in Indonesia and Austria in 2012, during which developers had the opportunity to visit the observatories, or during summer schools held in diverse locations, including some in developing countries. We held such seminars at the 208th Symposium on Sustainable Humanosphere Science School 2012 in Indonesia, UN data analysis symposium 2012 at Graz, Austria, and International Space Weather Initiative MAGnetic Data Acquisition System (MAGDAS) School 2012 (Figure 5). In addition to these face-to-face meetings, we held two online seminars in 2013 using 


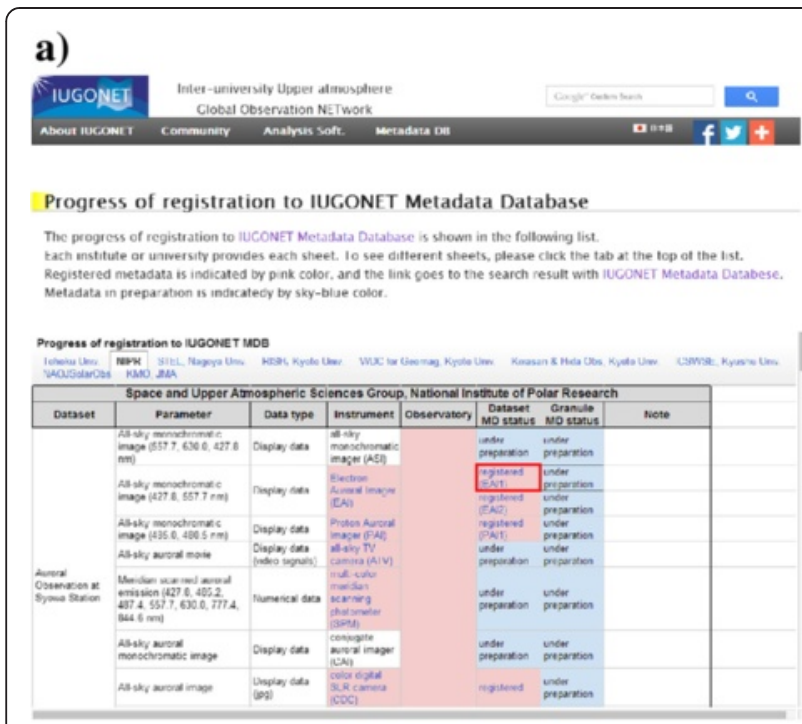

b)

All-gky auroral image taken by the Electron Auroral Lmager 1 (EAL-1) at Syowa Station. Antarctica. Disployouca

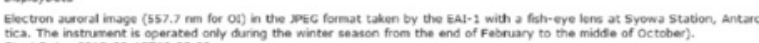

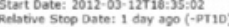

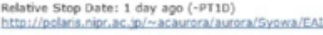

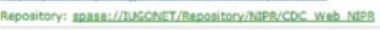

All-sky auroral image taken by the Electron Auroral Imager 1 (EAL-1) at Syowa Station, Antarctica. Displayouca

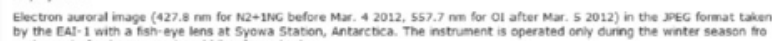
oy the end of February to the middile of october).

Start Date: 2011-03-01723:40:18

Stop Date: 2012-00-12T00:24:16

Figure 4 Example of the progress table of IUGONET MDDB (http://www.iugonet.org/en/mdblist.html). (a) Example of the National Institute of Polar Research. The pink (light blue)-colored cell means registered (under preparation). (b) Search results followed by clicking the red square in (a). (c) Example of the Solar-Terrestrial Environment Laboratory. Details are the same as in (a). (d) Available load procedure list (part) followed by clicking the red square in (c).

Internet conferencing systems, where many young scientists joined from Indonesia.

\section{Science-enabling service of the IUGONET}

As described above, about ten developers (researchers) are working exclusively for the IUGONET to build the MDDB/UDAS. In addition to the publication of technical

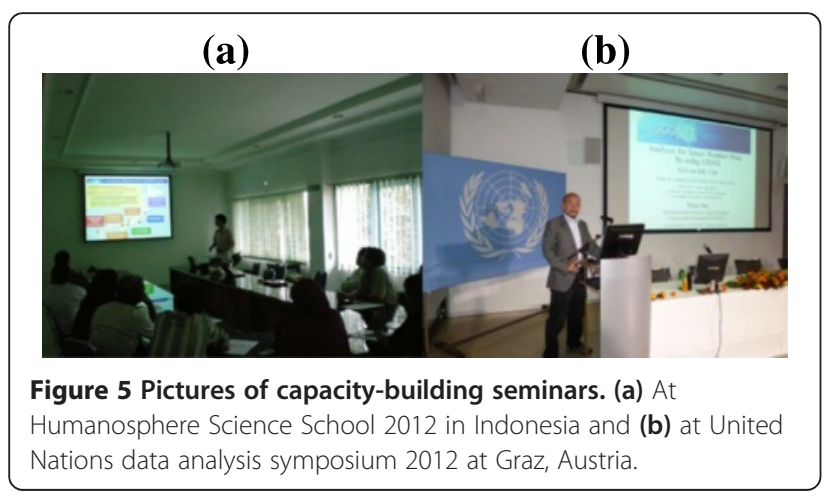

c)

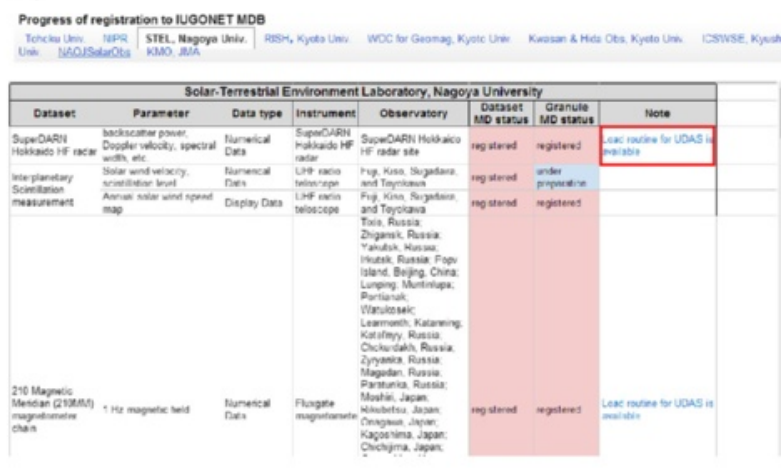

d)

\begin{tabular}{|c|c|c|c|}
\hline UDAS load routines & Observations data & Institutes & Photos/Movies/Docs \\
\hline ug._load_smart & $\begin{array}{l}\text { Solar images obtained by the SMMRT } \\
\text { telescope }\end{array}$ & $\begin{array}{l}\text { Kwatan \& Hida Obs, } \\
\text { Kyoto Univ. }\end{array}$ & - $2 / 0$ \\
\hline Nug.loud_iprt & Soler HF radio spectrun & Tohoku Univ. & ล $/ 0 / 0$ \\
\hline ug.Jand_ht_tohokus & $\begin{array}{l}\text { Jueiter's/solar wide band spectral data in } \\
\text { HF bazd }\end{array}$ & Tohoku Univ. & ค $/ 0 / 0$ \\
\hline Uog.lovd_aws_rish & $\begin{array}{l}\text { Surface meterology data taxen by the } \\
\text { autonatic westher station (uWs) }\end{array}$ & RISH, Kyoto Univ. & ด/0/u \\
\hline ug.laxd_bil_rish & Boundary layer racar & RISII, Kyoto Univ. & อ $/ 0 / 0$ \\
\hline wo._lave_.ter_rish & L-band lewer soposonere rads & RISH, Kyoto Univ. & ล $/ 0 / 0$ \\
\hline ug,land_eat & Equatoriul attrosphere racat & RISH, Kyoto Univ. & ล $10 / 0$ \\
\hline vug_loved_mu & MU radar & RiSH, Kyoto Univ. & - $/ 0 / 0$ \\
\hline vog_loud_meteor_rish & Meteor radar & RSSH, Kyoto Univ. & ค $/ 0 / D$ \\
\hline 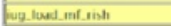 & MF tadat & RISH, Kyolo Univ. & ล $/ 0 / 0$ \\
\hline up_lovd_war_rish & Wind preflier radar & RISH, Kyoto Univ. & ล $0 / 0$ \\
\hline vg._load_ionosonde,_rish & $\begin{array}{l}\text { lonopram dista taken by the inosonde at } \\
\text { Shigaraki }\end{array}$ & RESII, Kyoto Univ. & ๑ $/ 0 / 0$ \\
\hline uq__load_raciosonde_rish & Radiosonce data & RISH, Kyoto Univ. & ล $/ 0 / 0$ \\
\hline ug_loud_sefit & SuperDARN radar & $\begin{array}{l}\text { N.PR Nagoya Univ. } \\
\text { And other } \\
\text { SuperDARN-related } \\
\text { organizations }\end{array}$ & ล $/ 0 / 0$ \\
\hline vig_land_ciscat & EISCAT radar & NIPR, Nagoya Unis. & ล $0 / 0$ \\
\hline
\end{tabular}




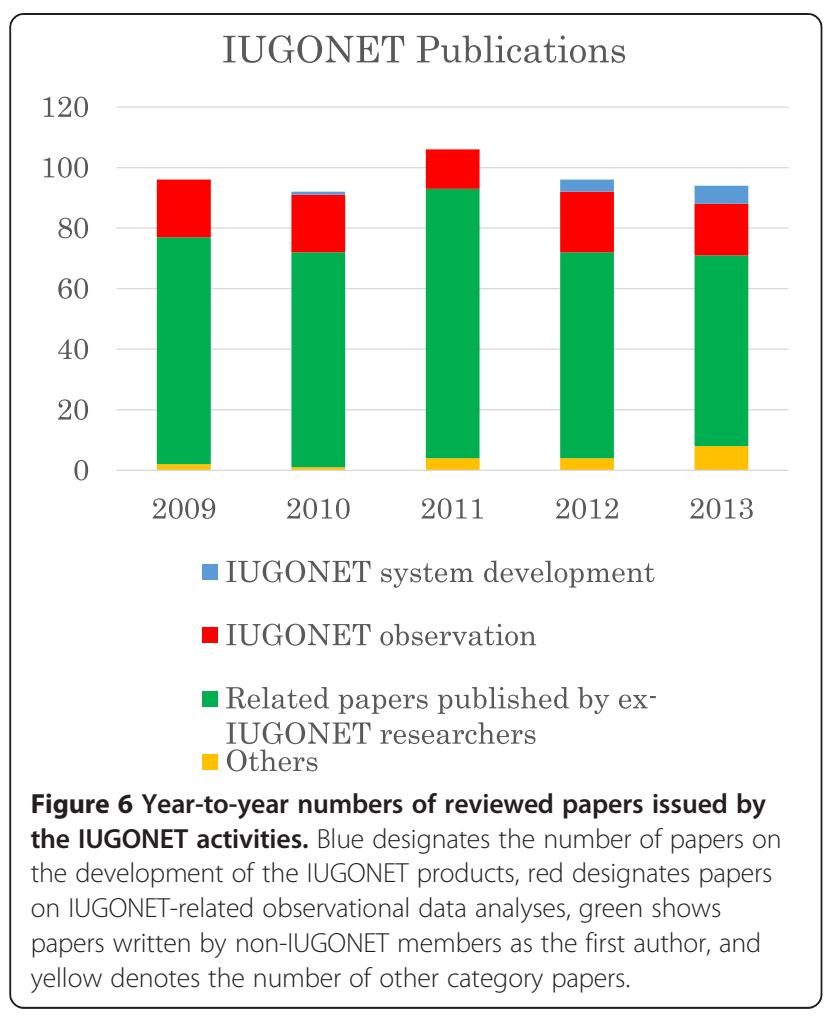

organized several sessions at international meetings, and because of both these international activities, the number of users of the IUGONET products is increasing.

Table 1 shows the countries that access the MDDB and the number of participants included in our mailing list according to their countries. In the 2 years since the release of the MDDB, about $80 \%$ of users have been from Japan, and the second and third highest users appear to be our cooperators associated with the SPASE and ESPAS communities. Among the other countries, our capacity-building activities in India, Indonesia, and Austria appear to have contributed to their greater access of our MDDB.

With regard to the mailing list that we started to compile in 2013, 85\% of participants are from within Japan. However, the numbers of participants from India and Indonesia, where we have undertaken capacity-building activities, including domestic education to foreign students/PDs, are relatively high. Although the numbers are small, we do have participants from all continents and regions except Oceania (Asia, North/South America, Europe, Africa, and the Middle East).

\section{Discussion}

As described above, registration of the MD is performed by postdoctoral fellows and other members of the STP community. This provides both the users of the MDDB and the postdoctoral fellows with greater understanding of the data and of their systems of observation. In
Table 1 Countries that are associated with IUGONET activities

\begin{tabular}{|c|c|c|}
\hline Access to MDDB (top ten countries) & Mailing list & \\
\hline Japan (approximately 80\%) & Japan & 126 \\
\hline$U^{a}$ & India & 8 \\
\hline Germany $^{a}$ & Indonesia ${ }^{\mathrm{b}}$ & 5 \\
\hline Ukraine & Taiwan & 3 \\
\hline Austriab $^{\text {b }}$ & $U S^{a}$ & 3 \\
\hline Indiab & Australia & 2 \\
\hline Indonesia $^{\mathrm{b}}$ & China & 2 \\
\hline Russia & Finland & 2 \\
\hline France & Nigeria & 2 \\
\hline China & Brazil & 1 \\
\hline \multirow[t]{6}{*}{ (Others) } & Egypt & 1 \\
\hline & Germany $^{\mathrm{a}}$ & 1 \\
\hline & Iraq & 1 \\
\hline & Korea & 1 \\
\hline & Malaysia & 1 \\
\hline & Thailand & 1 \\
\hline
\end{tabular}

(Left) Top ten countries accessing the IUGONET MDDB. (Right) Nationalities of the participants in the IUGONET mailing list (as of 15 July 2014). ${ }^{a}$ Countries cooperating in promoting research. ${ }^{b}$ Countries that have received training seminars.

addition, the international outreach/capacity-building lecture activities provide good experience for both the students and the facilitator of the training seminar.

Although the UDAS is a powerful tool for acquiring, displaying, and analyzing data, the main software components differ considerably from those used by the science community at large. Therefore, the interoperability of such tools should be improved by using other suitable software, for example, that being used by the meteorological community.

The capacity-building activities of the IUGONET have been linked to the activities of several institutions, e.g., the MAGDAS School and the RISH/Kyoto University's Equatorial Atmosphere Radar site. These institutional capacity-building activities are performed independently under the CAWSES-II program (Ueno et al. 2013). However, we hope that in the future, the IUGONET will take a role in networking these capacity-building activities.

The IUGONET facilitates exchange of data information (MD) on the Internet. Because we carefully selected the international 'standard' of the format of the MD and general design of the analysis software, our tool can be linked easily with other research activities, e.g., satellite missions in the upper atmosphere and other databases such as the Solar-Terrestrial Data Analysis and Reference System (Murata et al. 2002; Kunitake et al. 2013). We believe that our long-term database will play an important role for the international scientific community. In particular, we have 
contributed to the building of a database that enables users to search effectively and access the global database obtained through international cooperative projects such as the IGY and CAWSES. However, promoting the use of the IUGONET's tools will not succeed without international and open data exchange. We hope that the SCOSTEP and WDS will promote such exchange. It would be helpful for us if the SCOSTEP sets a general regulation regarding the opening of data, as do other international science communities, e.g., meteorology and hydrology, such as setting the maximum moratorium period to 1 or 2 years for data obtained by international scientific projects.

\section{Conclusions}

- The IUGONET is a Japanese project that aims to construct an online system to provide an MD database and analysis tool for upper atmospheric research. These have been released on our website (IUGONET 2014b).

- The usefulness of the IUGONET has been proven by the increasing number of domestic and international accesses to its website by researchers from a variety of disciplines. International collaborations between the IUGONET and other data networks, such as ESPAS and SPASE, are continuing to secure interoperability.

- The IUGONET is an excellent tool for educating students and young scientists in developing countries because of its well-documented database and instructive analysis tools.

- The IUGONET community has been contributing to SCOSTEP programs, and it will collaborate with SCOSTEP's new program, the 'Variability of the Sun and Its Terrestrial Impact,' not only in its scientific activities, but also in the establishment of E-infrastructure and capacity building.

- We welcome any kind of cooperation, including increasing the interoperability and MD exchange among the database development groups.

\section{Availability and requirements}

Project name: Inter-university Upper atmosphere Global Observation NETwork (IUGONET) project

Project home page: http://www.iugonet.org/en/ Operating system(s): Windows, Mac OS, Linux Programming language: IDL (for full use of UDAS/ SPEDAS including command line tools)

Other requirements: SPEDAS (for use of UDAS)

License: IDL license (for full use of UDAS)

Any restrictions to use by non-academics: Any IUGONET products are freely available from the home page with the exception of IDL license for full use of UDAS.

\section{Additional files}

Additional file 1: IUGONET_Observatory.KMZ. A KMZ file for Google Earth to show the locations of IUGONET observatories and each link to the metadata database.

Additional file 2: IUGONET_Instrument.KMZ. A KMZ file for Google Earth to show the location and parameters of IUGONET instruments and each link to the metadata database.

\section{Abbreviations}

CAWSES: Climate And Weather of the Sun-Earth System; CEDAR: Coupling, Energetics, and Dynamics of Atmospheric Regions; ESPAS: A European project titled the near-earth space data infrastructure for e-science;

ICSU: International Council of Scientific Unions; IGY: International Geophysical Year; IUGONET: Inter-university Upper atmosphere Global Observation NETwork; KML: formerly Keyhole Markup Language; MAGDAS: MAGnetic Data Acquisition System; MD: metadata; MDDB: metadata database;

NASA: National Aeronautics and Space Administration; NGDC: National Geophysical Data Center; NOAA: National Ocean and Atmosphere Administration; NSSDC: National Space Science Data Center; OMTI: Optical Mesosphere Thermosphere Imagers; SCOSTEP: Scientific Committee on Solar-Terrestrial Physics; SPASE: Space Physical Archive Search and Extract; STP: solar-terrestrial physics; SuperDARN: Super Dual Aurora Radar Network; UDAS: iUgonet Data Analysis Software; VarSITI: Variability of the Sun and Its Terrestrial Impact; VHO: Virtual Heliospheric Observatory; VMO: Virtual Magnetospheric Observatory; VSO: Virtual Solar Observatory; VxO: a Virtual Observatory; WDC: World Data Center; WDS: World Data System.

\section{Competing interests}

The authors declare that they have no competing interests.

\section{Authors' contributions}

The named authors contributed directly to the capacity-building activity of the IUGONET, and they are responsible for the documentation used in this paper. All authors read and approved the manuscript.

\section{Authors' information}

Except for the named authors, the IUGONET project team members as of 31 March 2014 are as follows (in alphabetical order within each institution): Masato Kagitani, Yasumasa Kasaba, Yuto Katoh, Atsushi Kumamoto, Hiroaki Misawa, Takahiro Obara, Takeshi Sakanoi, Naoki Terada, Fuminori Tsuchiya, Manabu Yagi (Tohoku University), Akira Kadokura, Hiroshi Miyaoka, Takuji Nakamura, Yasunobu Ogawa, Masaki Okada, Natsuo Sato, Yoshimasa Tanaka, Yoshihiro Tomikawa (National Institute of Polar Research), Ryoichi Fujii, Yoshizumi Miyoshi, Tatsuki Ogino, Yuichi Otsuka, Kazuo Shiokawa, Norio Umemura (Nagoya University), Jun-ichi Furumoto, Hiroyuki Hashiguchi, Toshihiko lyemori, Naoki Kaneda, Yukinobu Koyama, Masahito Nosé, Kazunari Shibata, Masahiko Takeda, Hiroaki Toh, Toshitaka Tsuda, Masanori Yabuki, Mamoru Yamamoto (Kyoto University), Daisuke Ikeda, Kiyohumi Yumoto, and Akimasa Yoshikawa (Kyushu University).

\section{Acknowledgements}

We express deep sadness at the passing of Professor Takayuki Ono in December 2013; he was the one of the five professors who started the IUGONET project. We appreciate the fruitful comments and discussions with Dr. Tohru Araki, Professor Figmeritus of Kyoto University. We also appreciate the very constructive comments of the two anonymous reviewers that helped us in revising and improving the manuscript. AY acknowledges the first executive director of the IUGONET, Dr. Hiroo Hayashi, as the succeeding director for June 2012 to March 2014.

\section{Author details}

'Solar-Terrestrial Environment Laboratory, Nagoya University, Furo-cho, Chikusa-ku, Nagoya 464-8601, Japan. ${ }^{2}$ National Institute of Polar Research, 10-3 Midori-cho, Tachikawa, Tokyo 190-8518, Japan. ${ }^{3}$ Research Institute for Sustainable Humanosphere, Kyoto University, Gokasho, Uji, Kyoto 611-0011, Japan. ${ }^{4}$ International Center for Space Weather Science and Education, Kyushu University, 6-10-1, Hakozaki, Higashi-ku, Fukuoka 812-8581, Japan. ${ }^{5}$ Kwasan and Hida Observatories, Graduate School of Science, Kyoto University, Kurabashira, Kamitakara-cho, Takayama, Gifu 506-1314, Japan. 
Received: 15 November 2014 Accepted: 10 December 2014

Published online: 08 January 2015

\section{References}

Abe S, Umemura N, Koyama Y, Tanaka Y, Yagi M, Yatagai A, Shinbori A, UeNo S, Sato Y, Kaneda N (2014) Progress of the IUGONET system - metadata database for upper atmosphere ground-based observation data. Earth Planets Space 66(11):133, doi:10.1186/1880-5981-66-133

Davila J, Tsuda T, Climate And Weather of the Sun-Earth System (CAWSES-II), http://www.cawses.org/CAWSES/Home.html. Accessed 7 Oct 2014

Grayzeck EJ, Welcome to the NSSDC! http://nssdc.gsfc.nasa.gov/. Accessed 7 Oct 2014 Gurman, JB, Virtual Solar Observatory. http://docs.virtualsolar.org/. Accessed 7 Oct 2014 Hamaguchi R (2013) A study on development of statistical analysis system for variations of atmospheric environment. Graduate School of Informatics, Kyoto University, Master Thesis (in Japanese)

Hayashi H, Koyama Y, Hori T, Tanaka Y, Abe S, Shinbori A, Kagitani M, Kouno T, Yoshida D, UeNo S, Kaneda N, Yoneda M, Umemura N, Tadokoro H, Motoba T, IUGONET project team (2013) Inter-university Upper Atmosphere Global Observation Network (IUGONET). Data Sci J 12:WDS179-WDS184, doi:10.2481/dsj.WDS-030

IUGONET (2014a) Progress of registration to IUGONET metadata database, http://www.iugonet.org/en/mdblist.html. Accessed 14 May 2014

IUGONET (2014b) IUGONET - Inter-university Upper atmosphere Global Observation NETwork, http://www.iugonet.org/en/. Accessed 7 May 2014

King T, Thieman J, Roberts DA (2010) SPASE 2.0: a standard data model for space physics. Earth Sci Inform 3:67-73, doi:10.1007/s12145-010-0053-4

Kunitake M, Yamamoto K, Watari S, Ukawa K, Kato H, Kimura E, Murayama Y, Murata KT (2013) Solar-Terrestrial data Analysis and Reference System (STARS) - its high potentiality for collaborative research. Data Sci J 12:WDS225-WDS228

McGuire R, SPDF - Coordinated Data Analysis Web (CDAWeb), http://cdaweb.gsfc. nasa.gov/about.html. Accessed 7 Oct 2014

Miyoshi Y, Ono T, Takashima T, Asamura K, Hirahara M, Kasaba Y, Matsuoka A, Kojima H, Shiokawa K, Seki K, Fujimoto M, Nagatsuma T, Cheng CZ, Kazama Y, Kasahara S, Mitani T, Matsumoto H, Higashio N, Kumamoto A, Yagitani S, Kasahara Y, Ishisaka K, Blomberg L, Fujimoto A, Katoh Y, Ebihara Y, Omura Y, Nose M, Hori T, Miyashita Y et al (2012) The Energization and Radiation in Geospace (ERG) Project. In: Summers D, Mann IR, Baker DN, Schulz M (eds) Dynamics of the Earth's radiation belts and inner magnetosphere, vol 199, Geophys. Monogr. Ser. AGU, Washington, D.C., pp 103-116. doi:10.1029/ 2012BK001304

Murata T, Okada M, Abe F, Araki T, Matsumoto H (2002) A design and estimation of distributed meta - database for Solar-Terrestrial Physics Observation Data, IPSJ Transaction on [database], No. SIG 12 (TOD 16), 115-130 (in Japanese with English abstract).

NOAA National Geophysical Data Center, SPIDR: SPIDR Home, http://spidr.ngdc. noaa.gov/spidr/. Accessed 7 Oct 2014

CAWSES Office, CAWSES - Home, http://www.bu.edu/cawses/. Accessed 7 Oct 2014

Rideout B., Welcome to the CEDAR Archival Madrigal Database, http://cedar. openmadrigal.org/. Accessed 7 Oct 2014

Tanaka Y-M, Shinbori A, Hori T, Koyama Y, Abe S, Umemura N, Sato Y, Yagi M, UeNo S, Yatagai A, Ogawa Y, Miyoshi Y (2013) Analysis software for upper atmospheric data developed by the IUGONET project and its application to polar science. Adv Polar Sci 24:231-240, doi:10.3724/SP.J.1085.2013.00231

The ESPAS Consortium, Welcome to the EU FP7 ESPAS Project, http://www. espas-fp7.eu/. Accessed 7 Oct 2014

UeNo S, Yumoto K, Yoshikawa A, Makita K, Munakata K, Mizuno A, Tsuda T (2013) Report of capacity-building activities of Japan during CAWSES-II period, (abstract/presentation of the CAWSES-II symposium).

Yatagai A, Tanaka Y, Abe S, Shinbori A, Yagi M, UeNo S, Koyama Y, Umemura N, Nosé M, Hori T, Sato Y, Hashiguchi NO, Kaneda N, IUGONET project team (2014) Interuniversity upper atmosphere global observation network (IUGONET) meta-database and analysis software. Data Sci J 13:DA37-PDA43

\section{Submit your manuscript to a SpringerOpen ${ }^{\circ}$ journal and benefit from:}

- Convenient online submission

- Rigorous peer review

- Immediate publication on acceptance

- Open access: articles freely available online

- High visibility within the field

- Retaining the copyright to your article

Submit your next manuscript at $\boldsymbol{\wedge}$ springeropen.com 